Pacific Journal of Mathematics

ON FUNCTIONAL EQUATIONS CONNECTED WITH
DIRECTED DIVERGENCE, INACCURACY AND GENERALIZED

DIRECTED DIVERGENCE 


\title{
ON FUNCTIONAL EQUATIONS CONNECTED WITH DIRECTED DIVERGENCE, INACCURACY AND GENERALIZED DIRECTED DIVERGENCE
}

\author{
Pl. Kannappan and C. T. NG
}

The measures directed divergence, inaccuracy as well as generalized directed divergence occurring in information theory can be characterized by the symmetry, expansibility, branching, and additivity properties together with some regularity and initial conditions. In this paper some functional equations generalizing those implicit in these characterizations shall be treated.

1. Introduction. Let $\Delta_{n}=\left\{P=\left(p_{1}, p_{2}, \cdots, p_{n}\right) \mid p_{i} \geqq 0\right.$ and $\left.\sum_{i=1}^{n} p_{i}=1\right\}$ and $\Delta_{n}^{\prime}=\left\{P=\left(p_{1}, p_{2}, \cdots, p_{n}\right) \mid p_{i}>0\right.$ and $\left.\sum_{i=1}^{n} p_{i} \leqq 1\right\}$ be the set of all finite complete and incomplete probability distributions respectively. In 1948 C. E. Shannon [16] introduced the following measure of information

$$
H_{n}(P)=-\sum_{i=1}^{n} p_{i} \log p_{i},
$$

on $\Delta_{n}$ which is now known as Shannon's entropy. This has been generalized to inaccuracy [10]. Inaccuracy and the related quantities directed divergence or information gain [11, 15] and generalized directed divergence [3] are given by

$$
\begin{gathered}
H_{n}(P \| Q)=-\sum_{i=1}^{n} p_{i} \log q_{i}, \quad\left(P \in \Delta_{n}, Q \in \Delta_{n} \text { or } \Delta_{n}^{\prime}\right), \\
I_{n}(P \| Q)=\sum_{i=1}^{n} p_{i} \log \frac{p_{i}}{q_{i}}, \quad\left(P \in \Delta_{n}, Q \in \Delta_{n} \text { or } \Delta_{n}^{\prime}\right),
\end{gathered}
$$

and

$$
D_{n}(P|| Q \mid R)=\sum_{i=1}^{n} p_{i} \log \frac{q_{2}}{r_{i}}, \quad\left(P \in \Delta_{n}, Q, R \in \Delta_{n} \text { or } \Delta_{n}^{\prime}\right)
$$

respectively. While characterizing these measures we come across the following functional equations

$$
\begin{gathered}
\sum_{i=1}^{n} \sum_{j=1}^{m} F\left(p_{i} q_{j}\right)=\sum_{i=1}^{n} F\left(p_{i}\right)+\sum_{j=1}^{m} F\left(q_{j}\right), \quad\left(P \in \Delta_{n}, Q \in \Delta_{m}\right), \\
\sum_{i=1}^{n} \sum_{j=1}^{m} F\left(p_{i} q_{j}, x_{i} y_{j}\right)=\sum_{i=1}^{n} F\left(p_{i}, x_{i}\right)+\sum_{j=1}^{m} F\left(q_{j}, y_{j}\right), \\
\left(P \in \Delta_{n}, Q \in \Delta_{m}, X \in \Delta_{n} \text { or } \Delta_{n}^{\prime}, Y \in \Delta_{m} \text { or } \Delta_{m}^{\prime}\right)
\end{gathered}
$$


and

$$
\begin{gathered}
\sum_{i=1}^{n} \sum_{j=1}^{m} F\left(p_{\imath} q_{j}, x_{\imath} y_{j}, u_{\imath} v_{j}\right)=\sum_{i=1}^{n} F\left(p_{i}, x_{i}, u_{\imath}\right)+\sum_{j=1}^{m} F\left(q_{j}, y_{j}, v_{j}\right), \\
\left(P \in \Delta_{n}, Q \in \Delta_{m}, X, U \in \Delta_{n} \text { or } \Delta_{n}^{\prime}, Y, V \in \Delta_{m} \text { or } \Delta_{m}^{\prime}\right)
\end{gathered}
$$

(cf. [2], [4], [5], [6], [7], [8], [9], [13]).

For the motivation to consider (1.6) and (1.7) and the application of this result, refer to the Remark at the end of this paper.

In this paper we consider the functional equation

$$
\begin{aligned}
\sum_{i=1}^{2} \sum_{j=1}^{3} F_{i j}\left(p_{i} q_{j}, x_{\imath} y_{\imath}\right)=\sum_{i=1}^{2} G_{\imath}\left(p_{i}, x_{\imath}\right)+\sum_{j=1}^{3} H_{j}\left(q_{j}, y_{j}\right), & \left(P \in \Delta_{2}, Q \in \Delta_{3}, X \in \Delta_{2}^{\prime}, Y \in \Delta_{3}^{\prime}\right)
\end{aligned}
$$

for unknown functions $F_{i, j}, G_{i}, H_{j}$. Then this gives the measurable solutions of (1.6) for all $P \in \Delta_{2}, Q \in \Delta_{3}, X \in \Delta_{2}^{\prime}, Y \in \Delta_{3}^{\prime}$ as a special case. The measurable solution of (1.7) for $P \in \Delta_{2}, Q \in \Delta_{3}, X, U \in \Delta_{2}^{\prime}, Y, V \in \Delta_{3}^{\prime}$ can also be obtained by a reduction to (1.8).

In solving (1.8) we make use of the following result of C. T. $\mathrm{Ng}$ [13]:

THEOREM 1.1. The measurable solutions of the functional equation

$$
\sum_{i=1}^{2} \sum_{j=1}^{3} F_{i, j}\left(p_{i} q_{j}\right)=\sum_{i=1}^{2} G_{i}\left(p_{\imath}\right)+\sum_{j=1}^{3} H_{j}\left(q_{j}\right)
$$

for all $P \in A_{2}, Q \in A_{3}$, are given by

$$
\left\{\begin{aligned}
H_{1}(q)=a q \log q+b_{1} q+c_{1}, H_{2}(q)=a q \log q+\left(b_{1}+d\right) q+c_{4}, \\
H_{3}(q)=a q \log q+\left(b_{1}+e\right) q+c_{7}, F_{11}(p)=a p \log p+b_{2} p+c_{2}, \\
F_{12}(p)=a p \log p+\left(b_{2}+d\right) p+c_{5}, \\
F_{1,3}(p)=a p \log p+\left(b_{2}+e\right) p+c_{8}, \\
F_{2,1}(p)=a p \log p+b_{3} p+c_{3}, F_{22}(p)=a p \log p+\left(b_{3}+d\right) p+c_{6}, \\
F_{2,3}(p)=a p \log p+\left(b_{3}+e\right) p+c_{9}, G_{1}(p)=g(p), \\
G_{2}(p)=-g(1-p)+a[p \log p+(1-p) \log (1-p)] \\
\quad+\left(b_{3}-b_{2}\right) p+\left(b_{2}-b_{1}\right)-c_{1}+c_{2}+c_{3}-c_{4}+c_{5}+c_{6} \\
\quad-c_{7}+c_{8}+c_{9},
\end{aligned}\right.
$$

where $a, b_{1}, b_{2}, b_{3}, c_{1}, c_{2}, \cdots, c_{9}, d$, e are arbitrary constants and $g$ is an arbitrary measurable function.

2. Measurable solutions of the functional equations (1.6) and (1.8). We first suppose that equation (1.8) is to hold for all $P \in \Delta_{2}$, $Q \in \Delta_{3}, X \in \Delta_{2}^{\prime}, Y \in \Delta_{3}^{\prime}$, where $\left.F_{i, j}, G_{i}, H_{j}:[0,1] \times\right] 0,1[\rightarrow R$ are functions measurable in their first variables. 
For arbitrarily fixed $x_{i}, y_{j}$ in ]0, $1\left[\right.$ with $\sum_{i=1}^{2} x_{i} \leqq 1, \sum_{j=1}^{3} y_{j} \leqq 1$, equation (1.8) is of the form (1.9) in the $p_{i}$ 's and $q_{j}^{\prime}$ 's. Therefore, by Theorem 1.1 there exist ' constants' $a\left(x_{1}, x_{2}, y_{1}, y_{2}, y_{3}\right), b_{i}\left(x_{1}, x_{2}, y_{1}, y_{2}, y_{3}\right)$, $i=1,2,3, c_{j}\left(x_{1}, x_{2}, y_{1}, y_{2}, y_{3}\right), j=1,2, \cdots, 9, d\left(x_{1}, x_{2}, y_{1}, y_{2}, y_{3}\right), e\left(x_{1}, x_{2}\right.$, $\left.y_{1}, y_{2}, y_{3}\right)$ and a measurable function $g\left(\cdot, x_{1}, x_{2}, y_{1}, y_{2}, y_{3}\right)$ such that

$$
\begin{aligned}
& \left(H_{1}\left(q, y_{1}\right)=a\left(x_{1}, x_{2}, y_{1}, y_{2}, y_{3}\right) q \log q+b_{1}\left(x_{1}, x_{2}, y_{1}, y_{2}, y_{3}\right) q\right. \\
& +c_{1}\left(x_{1}, x_{2}, y_{1}, y_{2}, y_{3}\right) \text {, } \\
& H_{2}\left(q, y_{2}\right)=a\left(x_{1}, x_{2}, y_{1}, y_{2}, y_{3}\right) q \log q+\left(b_{1}+d\right)\left(x_{1}, x_{2}, y_{1}, y_{2}, y_{3}\right) q \\
& +c_{4}\left(x_{1}, x_{2}, y_{1}, y_{2}, y_{3}\right) \text {, } \\
& H_{3}\left(q, y_{3}\right)=a\left(x_{1}, x_{2}, y_{1}, y_{2}, y_{3}\right) q \log q+\left(b_{1}+e\right)\left(x_{1}, x_{2}, y_{1}, y_{2}, y_{3}\right) q \\
& +c_{7}\left(x_{1}, x_{2}, y_{1}, y_{2}, y_{3}\right) \text {, } \\
& F_{1,1}\left(p, x_{1} y_{1}\right)=a\left(x_{1}, x_{2}, y_{1}, y_{2}, y_{3}\right) p \log p+b_{2}\left(x_{1}, x_{2}, y_{1}, y_{2}, y_{3}\right) p \\
& +c_{2}\left(x_{1}, x_{2}, y_{1}, y_{2}, y_{3}\right) \text {, } \\
& F_{1,2}\left(p, x_{1} y_{2}\right)=a\left(x_{1}, x_{2}, y_{1}, y_{2}, y_{3}\right) p \log p+\left(b_{2}+d\right)\left(x_{1}, x_{2}, y_{1}, y_{2}, y_{3}\right) p \\
& +c_{5}\left(x_{1}, x_{2}, y_{1}, y_{2}, y_{3}\right) \text {, } \\
& F_{1,3}\left(p, x_{1} y_{3}\right)=a\left(x_{1}, x_{2}, y_{1}, y_{2}, y_{3}\right) p \log p+\left(b_{2}+e\right)\left(x_{1}, x_{2}, y_{1}, y_{2}, y_{3}\right) p \\
& +c_{8}\left(x_{1}, x_{2}, y_{1}, y_{2}, y_{3}\right) \text {, } \\
& F_{2,1}\left(p, x_{2} y_{1}\right)=a\left(x_{1}, x_{2}, y_{1}, y_{2}, y_{3}\right) p \log p+b_{3}\left(x_{1}, x_{2}, y_{1}, y_{2}, y_{3}\right) p \\
& +c_{3}\left(x_{1}, x_{2}, y_{1}, y_{2}, y_{3}\right) \text {, } \\
& F_{2,2}\left(p, x_{2} y_{2}\right)=a\left(x_{1}, x_{2}, y_{1}, y_{2}, y_{3}\right) p \log p+\left(b_{3}+d\right)\left(x_{1}, x_{2}, y_{1}, y_{2}, y_{3}\right) p \\
& +c_{6}\left(x_{1}, x_{2}, y_{1}, y_{2}, y_{3}\right) \text {, } \\
& F_{2,3}\left(p, x_{2} y_{3}\right)=\alpha\left(x_{1}, x_{2}, y_{1}, y_{2}, y_{3}\right) p \log p+\left(b_{3}+e\right)\left(x_{1}, x_{2}, y_{1}, y_{2}, y_{3}\right) p \\
& +c_{9}\left(x_{1}, x_{2}, y_{1}, y_{2}, y_{3}\right) \text {. } \\
& G_{1}\left(p, x_{1}\right)=g\left(p, x_{1}, x_{2}, y_{1}, y_{2}, y_{3}\right) \text {, } \\
& G_{2}\left(p, x_{2}\right)=-g\left(1-p, x_{1}, x_{2}, y_{1}, y_{2}, y_{3}\right)+a\left(x_{1}, x_{2}, y_{1}, y_{2}, y_{3}\right)[p \log p \\
& +(1-p) \log (1-p)]+\left(b_{3}-b_{2}\right)\left(x_{1}, x_{2}, y_{1}, y_{2}, y_{3}\right) p \\
& +\left(b_{2}-b_{1}-c_{1}+c_{2}+c_{3}-c_{4}+c_{5}+c_{6}-c_{7}+c_{8}\right. \\
& \left.+c_{9}\right)\left(x_{1}, x_{2}, y_{1}, y_{2}, y_{3}\right) \text {. }
\end{aligned}
$$

From (2.1) we get

$$
a\left(x_{1}, x_{2}, y_{1}, y_{2}, y_{3}\right) \equiv \text { constant }=a
$$

and

$$
\left\{\begin{array}{l}
b_{1}\left(x, x_{2}, y_{1}, y_{2}, y_{3}\right) \equiv \text { a function of } y_{1} \text { only }=b_{1}\left(y_{1}\right) \\
b_{1}\left(y_{1}\right)+d\left(x_{1}, x_{2}, y_{1}, y_{2}, y_{3}\right) \equiv \text { a function of } y_{2}=\theta_{1}\left(y_{2}\right), \\
b_{1}\left(y_{1}\right)+e\left(x_{1}, x_{2}, y_{1}, y_{2}, y_{3}\right) \equiv \text { a function of } y_{3}=\phi_{1}\left(y_{3}\right) \\
b_{2}\left(x_{1}, x_{2}, y_{1}, y_{2}, y_{3}\right) \equiv \text { a function of } x_{1} y_{1}=b_{2}\left(x_{1} y_{1}\right)
\end{array}\right.
$$




$$
\left\{\begin{array}{l}
b_{2}\left(x_{1} y_{1}\right)+d\left(x_{1}, x_{2}, y_{1}, y_{2}, y_{3}\right) \equiv \text { a function of } x_{1} y_{2}=\theta_{2}\left(x_{1} y_{2}\right) \\
b_{2}\left(x_{1} y_{1}\right)+e\left(x_{1}, x_{2}, y_{1}, y_{2}, y_{3}\right) \equiv \text { a function of } x_{1} y_{3}=\phi_{2}\left(x_{1} y_{3}\right) \\
b_{3}\left(x_{1}, x_{2}, y_{1}, y_{2}, y_{3}\right) \equiv \text { a function of } x_{2} y_{1}=b_{3}\left(x_{2} y_{1}\right) \\
b_{3}\left(x_{2} y_{1}\right)+d\left(x_{1}, x_{2}, y_{1}, y_{2}, y_{3}\right) \equiv \text { a function of } x_{2} y_{2}=\theta_{3}\left(x_{2} y_{2}\right) \\
b_{3}\left(x_{2} y_{1}\right)+e\left(x_{1}, x_{2}, y_{1}, y_{2}, y_{3}\right) \equiv \text { a function of } x_{2} y_{3}=\phi_{3}\left(x_{2} y_{3}\right)
\end{array}\right.
$$

where $x_{i}, y_{j}$ are in ]0, 1 [ with $\sum_{i=1}^{2} x_{i} \leqq 1$ and $\sum_{j=1}^{3} y_{j} \leqq 1$.

Similarly

$$
\left\{\begin{array}{l}
c_{1}\left(x_{1}, x_{2}, y_{1}, y_{2}, y_{3}\right)=c_{1}\left(y_{1}\right) \\
c_{2}\left(x_{1}, x_{2}, y_{1}, y_{2}, y_{3}\right)=c_{2}\left(x_{1} y_{1}\right) \\
c_{3}\left(x_{1}, x_{2}, y_{1}, y_{2}, y_{3}\right)=c_{3}\left(x_{2} y_{1}\right) \\
c_{4}\left(x_{1}, x_{2}, y_{1}, y_{2}, y_{3}\right)=c_{4}\left(y_{2}\right) \\
c_{5}\left(x_{1}, x_{2}, y_{1}, y_{2}, y_{3}\right)=c_{5}\left(x_{1} y_{2}\right) \\
c_{6}\left(x_{1}, x_{2}, y_{1}, y_{2}, y_{3}\right)=c_{6}\left(x_{2} y_{2}\right) \\
c_{7}\left(x_{1}, x_{2}, y_{1}, y_{2}, y_{3}\right)=c_{7}\left(y_{3}\right) \\
c_{8}\left(x_{1}, x_{2}, y_{1}, y_{2}, y_{3}\right)=c_{8}\left(x_{1} y_{3}\right) \\
c_{9}\left(x_{1}, x_{2}, y_{1}, y_{2}, y_{3}\right)=c_{9}\left(x_{2} y_{3}\right)
\end{array}\right.
$$

where $x_{i}, y_{j}$ are in ]0,1[ with $\sum_{i=1}^{2} x_{i} \leqq 1$ and $\sum_{j=1}^{3} y_{j} \leqq 1$.

The simultaneous equations (2.4) are equivalent to

$$
\left\{\begin{aligned}
d\left(x_{1}, x_{2}, y_{1}, y_{2}, y_{3}\right) & =\theta_{1}\left(y_{2}\right)-b_{1}\left(y_{1}\right)=\theta_{2}\left(x_{1} y_{2}\right)-b_{2}\left(x_{1} y_{1}\right) \\
& =\theta_{3}\left(x_{2} y_{2}\right)-b_{3}\left(x_{2} y_{2}\right) \\
e\left(x_{1}, x_{2}, y_{1}, y_{2}, y_{3}\right) & =\phi_{1}\left(y_{3}\right)-b_{1}\left(y_{1}\right)=\phi_{2}\left(x_{1} y_{3}\right)-b_{2}\left(x_{1} y_{1}\right) \\
& =\phi_{3}\left(x_{2} y_{3}\right)-b_{3}\left(x_{2} y_{1}\right)
\end{aligned}\right.
$$

where $x_{i}, y_{j}$ are in $] 0,1\left[\right.$ with $x_{1}+x_{2} \leqq 1, y_{1}+y_{2}+y_{3} \leqq 1$.

We shall give the general solutions of equation (2.6) through the following lemma.

LEMma 2.1. The general solutions of the functional equation

$$
f(r s)-g(r t)=h(s)-k(t),
$$

for all $r, s, t \in] 0,1[$ with $s+t \leqq 1$, are given by

$$
\left\{\begin{array}{l}
f(x)=\psi(x)+A, \\
g(x)=\psi(x)+A+C, \\
h(x)=\psi(x)+B, \\
k(x)=\psi(x)+B+C,
\end{array}\right.
$$

for all $x \in] 0,1[$, where $A, B, C$ are constants and $\psi:] 0, \infty[\rightarrow R$ (reals) 
is a solution of the Cauchy equation,

$$
\psi(r s)=\psi(r)+\psi(s) .
$$

Proof. We rewrite equation (2.7) as

$$
f(r s)-h(s)=g(r t)-k(t),
$$

for all $r, s, t \in] 0,1[$ with $s+t \leqq 1$. Thus $f(r s)-h(s)$ is a function of $r$ only, say

$$
f(r s)-h(s)=l(r),
$$

for all $r, s \in] 0,1[$. Thus by [11, p. 59] there exists $\psi:] 0, \infty[\rightarrow \boldsymbol{R}$ satisfying

$$
\psi(r s)=\psi(r)+\psi(s),
$$

for all $r, s \in] 0, \infty$ [ such that it represents $f, h$, and $l$ through the equations

$$
\left\{\begin{array}{l}
f(x)=\psi(x)+A, \\
h(x)=\psi(x)+B, \\
l(x)=\psi(x)+A-B,
\end{array}\right.
$$

for all $x \in] 0,1[$, where $A$ and $B$ are arbitrary constants. Similarly $g$ and $k$ are given by

$$
\left\{\begin{array}{l}
g(x)=\psi(x)+A+C, \\
k(x)=\psi(x)+B+C,
\end{array}\right.
$$

for all $x \in] 0,1[$ and where $C$ is an arbitrary constant. This completes the proof of Lemma 2.1.

Thus the general solution of the equations (2.6) is given by

$$
\begin{cases}b_{\imath}(x)=\psi(x)+A_{i}, & i=1,2,3 \\ \theta_{i}(x)=\psi(x)+A_{i}+B, & i=1,2,3 \\ \phi_{i}(x)=\psi(x)+A_{\imath}+C, & i=1,2,3\end{cases}
$$

for all $x \in] 0,1\left[\right.$, where $A_{i}, B, C$ are constants and $\psi$ is a solution of the Cauchy equation (2.9).

Now we shall determine the function $g$ and the 'constants' $c_{i}$ 's in equation (2.2). We prepare our result by the following lemma.

LeMmA 2.2. Let $\left.k_{i}:\right] 0,1[\rightarrow R, i=1,2,3$ be functions satisfying the functional equation

$$
k_{1}(r)+k_{2}(r s)+k_{3}(r t)=T(s, t)
$$


for all $r, s, t \in] 0,1[$ with $s+t \leqq 1$. Then, and only then, there exist functions $\psi, \phi:] 0, \infty[\rightarrow \boldsymbol{R}$ which are solutions of (2.9) and constants $A, B, C$ such that

$$
\left\{\begin{array}{l}
k_{1}(x)=-\psi(x)-\phi(x)+C, \\
k_{2}(x)=\psi(x)+A, \\
k_{3}(x)=\phi(x)+B .
\end{array}\right.
$$

Proof. As the right side of (2.15) is independent of $r$, we have

$$
k_{1}(r)+k_{2}(r s)+k_{3}(r t)=k_{1}\left(r^{\prime}\right)+k_{2}\left(r^{\prime} s\right)+k_{3}\left(r^{\prime} t\right),
$$

for all $\left.r, r^{\prime}, s, t \in\right] 0,1\left[\right.$ with $s+t \leqq 1$. For arbitrary $\left.s, s^{\prime} \in\right] 0,1[$ we can choose $t \in] 0,1$ [ such that $s+t, s^{\prime}+t \leqq 1$ and thus from (2.17) we get

$$
k_{2}(r s)-k_{2}\left(r^{\prime} s\right)=k_{2}\left(r s^{\prime}\right)-k_{2}\left(r^{\prime} s^{\prime}\right),
$$

for all $\left.r, r^{\prime}, s, s^{\prime} \in\right] 0,1\left[\right.$. We can now fix $r^{\prime}$ and $s^{\prime}$ arbitrarily and then equation (2.18) reduces to

$$
k_{2}(r s)=l_{1}(r)+l_{2}(s),
$$

for all $r, s \in] 0,1$, (for some functions $l_{i}$ ), which is an equation similar to (2.11). Thus there exists a function $\psi:] 0, \infty[\rightarrow R$ satisfying (2.9) such that

$$
k_{2}(x)=\psi(x)+A
$$

for all $x \in] 0,1[$, where $A$ is a constant. Similarly there exists $\phi:] 0, \infty[\rightarrow R$ satisfying (2.9) such that

$$
k_{3}(x)=\phi(x)+B,
$$

for all $x \in] 0,1\left[\right.$. If we replace $k_{2}, k_{3}$ by $\psi, \phi$ respectively in equation (2.17) while fixing $r^{\prime}$ we get $k_{1}$ as is in (2.16). This proves our lemma.

From equation (2.2), we see that $g$ is a function of $p$ and $x_{1}$ only, say

$$
g\left(p, x_{1}, x_{2}, y_{1}, y_{2}, y_{3}\right)=g\left(p, x_{1}\right) \text {. }
$$

Now, from equation (2.2), we see that $-c_{1}\left(y_{1}\right)+c_{2}\left(x_{1} y_{1}\right)+c_{3}\left(x_{2} y_{1}\right)$ is independent of $y_{1}$ and therefore by Lemma 2.2 we have

$$
\left\{\begin{array}{l}
c_{1}(x)=\psi_{1}(x)+\phi_{1}(x)+D_{1}, \\
c_{2}(x)=\psi_{1}(x)+E_{1}, \\
c_{3}(x)=\phi_{1}(x)+F_{1},
\end{array}\right.
$$


for all $x \in] 0,1$, where $\psi_{1}$ and $\phi_{1}$ are solutions of the equation (2.9) and $D_{1}, E_{1}, F_{1}$ are arbitrary constants. Similarly we have

$$
\left\{\begin{array}{l}
c_{4}(x)=\psi_{2}(x)+\phi_{2}(x)+D_{2}, \\
c_{5}(x)=\psi_{2}(x)+E_{2}, \\
c_{6}(x)=\varphi_{2}(x)+F_{2}, \\
c_{7}(x)=\psi_{3}(x)+\phi_{3}(x)+D_{3}, \\
c_{8}(x)=\psi_{3}(x)+E_{3}, \\
c_{9}(x)=\phi_{3}(x)+F_{3},
\end{array}\right.
$$

where $\psi_{2}, \phi_{2}, \psi_{3}, \phi_{3}$ are solutions of (2.9) again. If we replace the $c_{i}$ 's in the second equation of (2.2) by equations (2.20), (2.21), and (2.22) we see that $-g\left(1-p, x_{1}\right)-\psi\left(x_{1}\right) p+\psi\left(x_{1}\right)+\psi_{1}\left(x_{1}\right)+\psi_{2}\left(x_{1}\right)+\psi_{3}\left(x_{1}\right)$ is independent of $x_{1}$, say

$$
\begin{aligned}
g\left(1-p, x_{1}\right)= & g(1-p)-\psi\left(x_{1}\right) p+\psi\left(x_{1}\right) \\
& +\psi_{1}\left(x_{1}\right)+\psi_{2}\left(x_{1}\right)+\psi_{3}\left(x_{1}\right)
\end{aligned}
$$

for all $p \in[0,1]$ and $\left.x_{1} \in\right] 0,1[$, where $g:[0,1] \rightarrow \boldsymbol{R}$ is an arbitrary measurable function.

Combining equations (2.1), (2.2), (2.3), (2.4), (2.5), (2.14), (2.21), (2.22), and (2.23) we are ready to conclude the following theorem.

THEOREM 2.1. Let $\left.F_{i j}, G_{i}, H_{j}:[0,1] \times\right] 0,1[\rightarrow \boldsymbol{R}(i=1,2, j=$ $1,2,3)$ be functions which are measurable in their first variables. Then these functions satisfy the functional equation (1.8) if and only if there exist $\left.\psi, \psi_{2}, \phi_{2}:\right] 0, \infty[\rightarrow \boldsymbol{R}$ all satisfy the Cauchy equation (2.9) such that

$$
\left\{\begin{array}{l}
H_{1}(q, y)=a q \log q+\left[\psi(y)+A_{1}\right] q+\psi_{1}(y)+\phi_{1}(y)+D_{1}, \\
H_{2}(q, y)=a q \log q+\left[\psi(y)+A_{1}+B\right] q+\psi_{2}(y)+\phi_{2}(y)+D_{2}, \\
H_{3}(q, y)=a q \log q+\left[\psi(y)+A_{1}+c\right] q+\psi_{3}(y)+\phi_{3}(y)+D_{3}, \\
F_{1,1}(p, y)=a p \log p+\left[\psi(y)+A_{2}\right] p+\psi_{1}(y)+E_{1}, \\
F_{1,2}(p, y)=a p \log p+\left[\psi(y)+A_{2}+B\right] p+\psi_{2}(y)+E_{2}, \\
F_{1,3}(p, y)=a p \log p+\left[\psi(y)+A_{2}+c\right] p+\psi_{3}(y)+E_{3}, \\
F_{2,1}(p, y)=a p \log p+\left[\psi(y)+A_{3}\right] p+\phi_{1}(y)+F_{1}, \\
F_{2_{2}}(p, y)=a p \log p+\left[\psi(y)+A_{3}+B\right] p+\phi_{2}(y)+F_{2}, \\
F_{2,3}(p, y)=a p \log p+\left[\psi(y)+A_{3}+c\right] p+\phi_{3}(y)+F_{3}, \\
G_{1}(p, x)=g(p)+\psi(x) p+\psi_{1}(x)+\psi_{2}(x)+\psi_{3}(x), \\
G_{2}(p, x)=-g(1-p)+a[p \log p+(1-p) \log (1-p)] \\
\quad+\left[\psi(x)+A_{3}-A_{2}\right] p+\dot{\phi}_{1}(x)+\phi_{2}(x)+\phi_{3}(x)+A_{2}, \\
\quad-A_{1}-D_{1}-D_{2}-D_{3}+E_{1}+E_{2}+E_{3}+F_{1}+F_{2}+F_{3},
\end{array}\right.
$$


for all $p, q \in[0,1], x, y \in] 0,1\left[\right.$, where $a, A_{\imath}, B, c, D_{i}, E_{i}, F_{\imath}, i=1,2,3$, are all constants, and $g$ is an arbitrary measurable function.

Theorem 2.2. If $F:[0,1] \times] 0,1[\rightarrow \boldsymbol{R}$ is measurable in its first variable, then it satisfies the functional equation (1.6) for all $P \in \Delta_{2}$, $Q \in \Delta_{3}, X \in \Delta_{2}^{\prime}, Y \in \Delta_{3}^{\prime}$ if and only if $F$ is of the form

$$
F(p, x)=a p \log p+[\psi(x)+A] p,
$$

for all $p \in[0,1], x \in] 0,1[$, where $\psi$ is a solution of the Cauchy equation (2.9) and a, $A$ are constants.

3. On the measurable solutions of the functional equation (1.7). Let $F:[0,1] \times] 0,1[\times] 0,1[\rightarrow \boldsymbol{R}$ be measurable in its first variable and satisfy the equation (1.7) for all $P \in \Delta_{2}, Q \in \Delta_{3}, X, U \in \Delta_{2}^{\prime}$, $Y, V \in \Delta_{3}^{\prime}$.

For each fixed $u_{2}, v_{j}$ equation (1.7) reduces to the form (1.8). Thus by Theorem 2.1 there exist in particular $\psi, \psi_{1}, \psi_{2}, \phi_{1}, \phi_{2}$ satisfying the Cauchy equation (2.9) in their first variables and $A_{1}, A_{2}, A_{3}, \alpha_{\varsigma} B, D_{1}$, $D_{2}, E_{1}, E_{2}, F_{1}$ such that

$$
\begin{aligned}
& \left(F\left(q, y, v_{1}\right)=\alpha\left(u_{1}, u_{2}, v_{1}, v_{2}, v_{3}\right) q \log q+\left[\psi\left(y, u_{1}, u_{2}, v_{1}, v_{2}, v_{3}\right)\right.\right. \\
& \left.+A_{1}\left(u_{1}, u_{2}, v_{1}, v_{2}, v_{3}\right)\right] q+\left(\psi_{1}+\phi_{1}\right)\left(y, u_{1}, u_{2}, v_{1}, v_{2}, v_{3}\right) \\
& +D_{1}\left(u_{1}, u_{2}, v_{1}, v_{2}, v_{3}\right) \text {, } \\
& F\left(q, y, v_{2}\right)=a\left(u_{1}, u_{2}, v_{1}, v_{2}, v_{3}\right) q \log q+\left[\psi\left(y, u_{1}, u_{2}, v_{1}, v_{2}, v_{3}\right)\right. \\
& \left.+\left(A_{1}+B\right)\left(u_{1}, u_{2}, v_{1}, v_{2}, v_{3}\right)\right] q+\left(\psi_{2}+\phi_{2}\right) \\
& \left(y, u_{1}, u_{2}, v_{1}, v_{2}, v_{3}\right)+D_{2}\left(u_{1}, u_{2}, v_{1}, v_{2}, v_{3}\right) \text {, } \\
& F\left(q, y, u_{1} v_{1}\right)=a\left(u_{1}, u_{2}, v_{1}, v_{2}, v_{3}\right) q \log q+\left[\psi\left(y, u_{1}, u_{2}, v_{1}, v_{2}, v_{3}\right)\right. \\
& \left.+A_{2}\left(u_{1}, u_{2}, v_{1}, v_{2}, v_{3}\right)\right] q+\psi_{1}\left(y, u_{1}, u_{2}, v_{1}, v_{2}, v_{3}\right) \\
& +E_{1}\left(u_{1}, u_{2}, v_{1}, v_{2}, v_{3}\right) \text {, } \\
& F\left(q, y, u_{1} v_{2}\right)=a\left(u_{1}, u_{2}, v_{1}, v_{2}, v_{3}\right) q \log q+\left[\psi\left(y, u_{1}, u_{2}, v_{1}, v_{2}, v_{3}\right)\right. \\
& \left.+\left(A_{2}+B\right)\left(u_{1}, u_{2}, v_{1}, v_{2}, v_{3}\right)\right] q \\
& +\dot{\psi}_{2}\left(y, u_{1}, u_{2}, v_{1}, v_{2}, v_{3}\right)+E_{2}\left(u_{1}, u_{2}, v_{1}, v_{2}, v_{3}\right) \text {, } \\
& F\left(q, y, u_{2} v_{1}\right)=a\left(u_{1}, u_{2}, v_{1}, v_{2}, v_{3}\right) q \log q+\left[\psi\left(y, u_{1}, u_{2}, v_{1}, v_{2}, v_{3}\right)\right. \\
& \left.+A_{3}\left(u_{1}, u_{2}, v_{1}, v_{2}, v_{3}\right)\right] q+\dot{\phi}_{1}\left(y, u_{1}, u_{2}, v_{1}, v_{2}, v_{3}\right) \\
& +F_{1}\left(u_{1}, u_{2}, v_{1}, v_{2}, v_{3}\right) \text {. } \\
& a\left(u_{1}, u_{2}, v_{1}, v_{2}, v_{3}\right) \equiv a \text { constant }=a .
\end{aligned}
$$

Hence it follows that

$$
\begin{aligned}
& \psi\left(y, u_{1}, u_{2}, v_{1}, v_{2}, v_{3}\right)+A_{1}\left(u_{1}, u_{2}, v_{1}, v_{2}, v_{3}\right) \\
& \quad \equiv a \text { function of } y \text { and } v_{1} \text { only }=\theta\left(y, v_{1}\right),
\end{aligned}
$$




$$
\begin{aligned}
& \psi\left(y, u_{1}, u_{2}, v_{1}, v_{2}, v_{3}\right)+A_{1}\left(u_{1}, u_{2}, v_{1}, v_{2}, v_{3}\right)+B\left(u_{1}, u_{2}, v_{1}, v_{2}, v_{3}\right)=\theta\left(y, v_{2}\right), \\
& \psi\left(y, u_{1}, u_{2}, v_{1}, v_{2}, v_{3}\right)+A_{2}\left(u_{1}, u_{2}, v_{1}, v_{2}, v_{3}\right)=\theta\left(y, u_{1} v_{1}\right), \\
& \psi\left(y, u_{1}, u_{2}, v_{1}, v_{2}, v_{3}\right)+A_{2}\left(u_{1}, u_{2}, v_{1}, v_{2}, v_{3}\right)+B\left(u_{1}, u_{2}, v_{1}, v_{2}, v_{3}\right) \\
& \quad=\theta\left(y, u_{1} v_{2}\right) .
\end{aligned}
$$

From equations (3.3) to (3.6) we have

$$
\theta\left(y, v_{2}\right)-\theta\left(y, v_{1}\right)=\theta\left(y, u_{1} v_{2}\right)-\theta\left(y, u_{1} v_{1}\right)
$$

and

$$
A_{2}\left(u_{1}, u_{2}, v_{1}, v_{2}, v_{3}\right)-A_{1}\left(u_{1}, u_{2}, v_{1}, v_{2}, v_{3}\right)=\theta\left(y, u_{1} v_{1}\right)-\theta\left(y, v_{1}\right) .
$$

For (3.7), by Lemma 2.1 there exists, for each fixed $y$, a function $\theta_{1}(\cdot, y)$ satisfying the Cauchy equation (2.9) and a constant $\theta_{2}(y)$ such that, we have

$$
\theta(y, v)=\theta_{1}(v, y)+\theta_{2}(y) .
$$

Now equations (3.8) and (3.9) yield

$$
\theta_{1}(v, y) \equiv \text { a function of } v \text { alone }=\theta_{1}(v) .
$$

Thus we can rewrite the first equation of (3.1) as

$$
\begin{aligned}
F\left(q, y, v_{1}\right)= & a q \log q+\left[\theta_{1}\left(v_{1}\right)+O_{2}(y)\right] q \\
& +\left(\psi_{1}+\phi_{1}\right)\left(y, u_{1}, u_{2}, v_{1}, v_{2}, v_{3}\right)+D_{1}\left(u_{1}, u_{2}, v_{1}, v_{2}, v_{3}\right) .
\end{aligned}
$$

From (3.11) we see that $\left(\dot{\psi}_{1}+\dot{\phi}_{1}\right)\left(y, u_{1}, u_{2}, v_{1}, v_{2}, v_{3}\right)+D_{1}\left(u_{1}, u_{2}, v_{1}, v_{2}, v_{3}\right)$ depends on $y$ and $v_{1}$ only. Since $\psi_{1}, \dot{\phi}_{1}$ satisfy the Cauchy equation (2.9), $\left(\dot{\gamma}_{1}+\dot{\phi}_{1}\right)\left(y, u_{1}, u_{2}, v_{1}, v_{2}, v_{3}\right)$ and $D_{1}\left(u_{1}, u_{2}, v_{1}, v_{2}, v_{3}\right)$ depend on $\left(y, v_{1}\right)$ and $v_{1}$ only respectively. Thus we can write (3.11) in the form

$$
\begin{aligned}
F(q, y, v)= & a q \log q+\left[\theta_{1}(v)+\theta_{2}(y)\right] q \\
& +\alpha_{1}(y, v)+\alpha_{2}(v),
\end{aligned}
$$

where $\theta_{1}$ and $\alpha_{1}(\cdot, v)$ satisfy the Cauchy equation (2.9).

From the first, third, and fifth equations of (3.1) and (3.12) we have

$$
\alpha_{1}\left(y, v_{1}\right)=\alpha_{1}\left(y, u_{1} v_{1}\right)+\alpha_{1}\left(y, u_{2} v_{1}\right),
$$

for all $\left.u_{1}, u_{2}, v_{1} \in\right] 0,1\left[\right.$ with $u_{1}+u_{2} \leqq 1$. Hence $\alpha_{1}$ is independent of the second variable and we may write the equation (3.12) as

$$
F(q, y, v)=a q \log q+\left[\theta_{1}(v)+\theta_{2}(y)\right] q+\alpha_{1}(y)+\alpha_{2}(v),
$$

for all $q \in[0,1], y, v \in] 0,1\left[\right.$ where $\theta_{1}$ and $\alpha_{1}$ are solutions of the Cauchy 
equation (2.9). If we interchange the roles of the second and the third arguments of $F$ in the above procedure we see that $\theta_{2}, \alpha_{2}$ are also solutions of the Cauchy equation (2.9).

Substituting (3.13) into (1.7), taking into account that $\theta_{i}, \alpha_{i}$ are solutions of the Cauchy equation (2.9) we get $\alpha_{i} \equiv 0$. Thus we have proved the following theorem.

TheOREM 3.1. Let $F:[0,1] \times] 0,1[\times] 0,1[\rightarrow R$ be measurable in its first variable. Then $F$ satisfies the functional equation (1.7) if and only if $F$ has the form

$$
F(q, y, v)=a q \log q+\left[\theta_{1}(v)+\theta_{2}(y)\right] q,
$$

where $\left.\theta_{1}, \theta_{2}:\right] 0, \infty[\rightarrow \boldsymbol{R}$ satisfy the Cauchy equation (2.9).

Corollary 3.1. Let $F:([0,1] \times] 0,1[\times] 0,1[) \cup\{(0,0,[0,1[)\} \cup$ $\{(1,1] 0,1]),\} \cup\{(0,[0,1[, 0)\} \cup\{(1] 0,1], 1),\} \rightarrow R$ be measurable in its first variable. Then it satisfies the equation (1.7) if and only if $F$ has the form given by (3.14) on $[0,1] \times] 0,1[\times] 0,1[$ and on the boundary $F(0,0, \cdot) \equiv 0, F(1,1, \cdot)=\theta_{1}(\cdot), F(0, \cdot, 0) \equiv 0$ and $F(1, \cdot, 1)=\theta_{2}(\cdot)$.

REMARK. The measures $H_{n}, I_{n}, D_{n}$ in (1.2), (1.3), (1.4) possess in particular properties: (a) Symmetry: $H_{n}, I_{n}, D_{n}$ are symmetric in the pairs $\left(p_{i}, q_{i}\right),\left(p_{i}, q_{i}\right),\left(p_{i}, q_{i}, r_{i}\right)$ respectively, (b) Expansibility: If $P=$ $\left(p_{1}, p_{2}, \cdots, p_{n}\right), Q=\left(q_{1}, q_{2}, \cdots, q_{n}\right), R=\left(r_{1}, r_{2}, \cdots, r_{n}\right)$ and $P^{\prime}=\left(p_{1}, p_{2}, \cdots\right.$, $\left.p_{n}, 0\right), Q^{\prime}=\left(q_{1}, q_{2}, \cdots, q_{n}, 0\right), R^{\prime}=\left(r_{1}, r_{2}, \cdots, r_{n}, 0\right)$, then $H_{n}(P \| Q)=$ $H_{n+1}\left(P^{\prime} \| Q^{\prime}\right), I_{n}(P \| Q)=I_{n+1}\left(P^{\prime} \| Q^{\prime}\right)$ and $D_{n}(P \| Q \mid R)=D_{n+1}\left(P^{\prime}|| Q^{\prime} \mid R^{\prime}\right)$, (c) Branching: If $P=\left(p_{1}, p_{2}, \cdots, p_{n}\right), Q=\left(q_{1}, q_{2}, \cdots, q_{n}\right), R=\left(r_{1}, r_{2}\right.$, $\left.\cdots, r_{n}\right)$ and $P^{\prime}=\left(p_{1}+p_{2}, p_{3}, \cdots, p_{n}\right), Q^{\prime}=\left(q_{1}+q_{2}, q_{3}, \cdots, q_{n}\right)$ and $R^{\prime}=\left(r_{1}+r_{2}, r_{3}, \cdots, r_{n}\right)$, then $H_{n}(P \| Q)-H_{n-1}\left(P^{\prime} \| Q^{\prime}\right), I_{n}(P \| Q)-$ $I_{n-1}\left(P^{\prime} \| Q^{\prime}\right)$ and $D_{n}(P|| Q \mid R)-D_{n-1}\left(P^{\prime}|| Q^{\prime} \mid R\right)$ depend on $\left(p_{1}, p_{2}, q_{1}, q_{2}\right)$, $\left(p_{1}, p_{2}, q_{1}, q_{2}\right)$ and $\left(p_{1}, p_{2}, q_{1}, q_{2}, r_{1}, r_{2}\right)$ respectively. It is shown by C. T. $\mathrm{Ng}$ [14] that these three properties are equivalent to the representability of $H_{n}, I_{n}, D_{n}$ in the form $H_{n}(P \| Q)=\sum_{i=1}^{n} f\left(p_{i}, q_{i}\right)$, $I_{n}(P \| Q)=\sum_{i=1}^{n} g\left(p_{i}, q_{i}\right)$ and $D_{n}(P \| Q \mid R)=\sum_{i=1}^{n} h\left(p_{i}, q_{i}, r_{i}\right)$ where $f$, $g, h$ are any function satisfying $f(0,0)=g(0,0)=h(0,0,0)=0$. From these representations, the additivity property of these measures motivates the study of the functional equations (1.6) and (1.7).

The Theorems 2.2 and 3.1 lead to a characterization of directed divergence and inaccuracy and of generalized directed divergence respectively. These three measures are determined by (a) Symmetry, (b) Expansibility, (c) Branching, (d) Additivity, and (e) Regularity conditions such as Lebesgue measurability and appropriate initial conditions. 


\section{REFERENCES}

1. J. Aczél, Lectures on Functional Equations and Their Applications, Academic Press, New York, 1966.

2. J. Aczél and Z. Daróczy, Charalterisierung der Entropien positiver Ordnung und der Shannonschen Entropie, Acta Math. Acad. Sci. Hungar., 14 (1963), 95-121.

3. J. Aczél and P. Nath, Axiomatic characterization of some measures of divergence in information, Z. Wahrscheinlichkeitstheorie verw. Geb., 21 (1972), 215-224.

4. T. W. Chaundy and J. B. McLeod, On a functional equation, Edinburgh Math. Notes, 43 (1962), 7-8.

5. Z. Daróczy, On the measurable solutions of a functional equation, Acta Math. Acad. Sci. Hungar., 22 (1971), 11-14.

6. Pl. Kannappan, On Shannon's entropy, directed divergence and inaccuracy, Z. Wahrscheinlichkeitstheorie verw. Geb., 22 (1972), 95-100.

7. — On directed divergence and inaccuracy, Z. Wahrscheinlichkeitstheorie verw. Geb., 25 (1972), 49-55.

8. - On generalized directed divergence, Funk. Ekvacioj, 16 (1973), 71-77.

9. - On a functional equation connected with generalized directed divergence, Aequationes Math., (to appear).

10. D. F. Kerridge, Inaccuracy and inference, J. Royal Statist. Soc. Ser. B, 23 (1961), 184-194.

11. S. Kullback, Information Theory and Statistics, J. Wiley \& Sons, New York, 1959.

12. J. P. Mokanski, Extensions of functions satisfying Cauchy and Pexider type equations, Ph.D. Thesis, University of Waterloo, 1971.

13. C. T. $\mathrm{Ng}$, On the measurable solutions of the functional equation

$$
\sum_{i=1}^{2} \sum_{j=1}^{3} F_{i, j}\left(p_{i} q_{j}\right)=\sum_{i=1}^{2} G_{i}\left(p_{i}\right)+\sum_{j=1}^{3} H_{j}\left(q_{j}\right),
$$

Acta Math. Acad. Sci. Hungar., 25 (1974).

14. - Representation of measures of information with the branching property, Information and Control, 25 (1974), 45-56.

15. A. Rényi, On measures of entropy and information, Proc. Fourth Berkeley Sympos. Math. Statistics, Probab., (1960), 547-561.

16. C. E. Shannon, A mathematical theory of communication, Bell System Tech. J., 27 (1948), 378-423 and 623-656.

Received June 15, 1973 and in revised form January 16, 1974. This research is partially supported by NRC of Canada grants.

UNIVERSITY OF WATERLOO 



\section{PACIFIC JOURNAL OF MATHEMATICS}

\section{EDITORS}

RICHARD ARENS (Managing Editor)

University of California

Los Angeles, California 90024

R. A. Beaumont

University of Washington

Seattle, Washington 98105
J. DugundJI

Department of Mathematics University of Southern California Los Angeles, California 90007

D. Gilbarg AND J. Milgram Stanford University

Stanford, California 94305

\section{ASSOCIATE EDITORS}
E. F. BECKENBACH
B. H. NeUmanN
F. WOLF
K. YOSHIDA

\section{SUPPORTING INSTITUTIONS}

UNIVERSITY OF BRITISH COLUMBIA CALIFORNIA INSTITUTE OF TECHNOLOGY

UNIVERSITY OF CALIFORNIA

MONTANA STATE UNIVERSITY

UNIVERSITY OF NEVADA

NEW MEXICO STATE UNIVERSITY

OREGON STATE UNIVERSITY

UNIVERSITY OF OREGON

OSAKA UNIVERSITY
UNIVERSITY OF SOUTHERN CALIFOF

STANFORD UNIVERSITY

UNIVERSITY OF TOKYO

UNIVERSITY OF UTAH

WASHINGTON STATE UNIVERSITY UNIVERSITY OF WASHINGTON

AMERICAN MATHEMATICAL SOCIET NAVAL WEAPONS CENTER 


\section{Pacific Journal of Mathematics}

\section{Vol. 54, No. 1 \\ May, 1974}

Ralph K Amayo, Engel Lie rings with chain conditions ..................

Bernd Anger and Jörn Lembcke, Hahn-Banach type theorems for hypolinear

functionals on preordered topological vector spaces ..................

Gregory Frank Bachelis and Samuel Ebenstein, On $\Lambda(p)$ sets ................

Harvey Isaac Blau, Indecomposable modules for direct products of finite

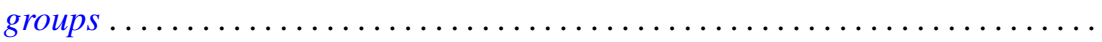

Larry Eugene Bobisud and James Calvert, Singular perturbation of a

time-dependent Cauchy problem in a Hilbert space ................

Walter D. Burgess and Robert Raphael, Abian's order relation and orthogonal

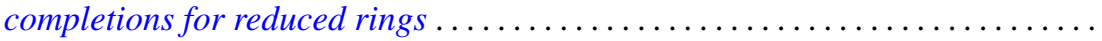

James Diederich, Representation of superharmonic functions mean continuous at

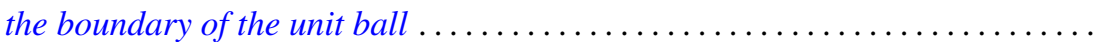

Aad Dijksma and Hendrik S. V. de Snoo, Self-adjoint extensions of symmetric

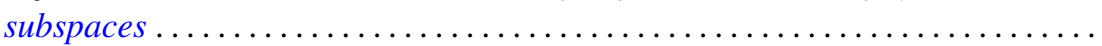

Gustave Adam Efroymson, A Nullstellensatz for Nash rings . . . . . . . . . . . . .

John D. Elwin and Donald R. Short, Branched immersions onto compact orientable surfaces . . . . . . . . . . . . . . . . . . . . . . . . .

John Douglas Faires, Comparison of the states of closed linear

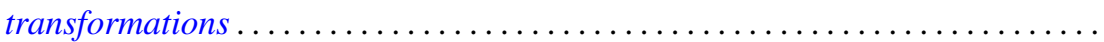

Joe Wayne Fisher and Robert L. Snider, On the von Neumann regularity of rings with regular prime factor rings .

Franklin Takashi Iha, A unified approach to boundary value problems on compact intervals

Palaniappan L. Kannappan and Che Tat $\mathrm{Ng}$, On functional equations connected with directed divergence, inaccuracy and generalized directed divergence

Samir A. Khabbaz and Elias Hanna Toubassi, The module structure of Ext $(F, T)$ over the endomorphism ring of $T$...

Garo K. Kiremidjian, On deformations of complex compact manifolds with boundary.

Dimitri Koutroufiotis, Mappings by parallel normals preserving principal

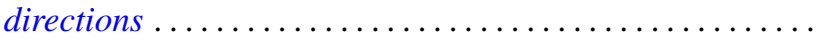

W. K. Nicholson, Semiperfect rings with abelian adjoint group

Norman R. Reilly, Extension of congruences and homomorphisms to translational hulls

Sadahiro Saeki, Symmetric maximal ideals in $M(G)$

Brian Kirkwood Schmidt, On the homotopy invariance of certain functors ...

H. J. Shyr and T. M. Viswanathan, On the radicals of lattice-ordered rings ...

Indranand Sinha, Certain representations of infinite group algebras ...

David Smallen, The group of self-equivalences of certain complexes ...

Kalathoor Varadarajan, On a certain problem of realization in homotopy

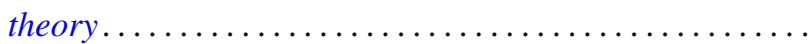

